American Journal of Agricultural and Biological Science 1 (1): 10-16, 2006

ISSN: $1557-4989$

(c) 2006 Science Publications

\title{
Estimating the Optimal Farm Size under Uncertainty: an Application of Real Options Methodology
}

\author{
Anastasios Ch. Michailidis and Konstadinos A. Mattas \\ Department of Agricultural Products Marketing and Quality Control, \\ Technological Education Institution of Western Macedonia, Greece
}

\begin{abstract}
Farm structure and optimal farm size have always attracted the interest of research as they constitute some of the intense problems of farm efficiency and farm income. Although several approached have been employed to handle with this problem a real options approach can significantly contribute on this matter. This article provides an empirical example of applying real options approach in investigating a typical Greek farm in the town of Velvendo. Several scenarios are used to estimate the optimal farm size employing both discounted cash flow (DCF) methods and real options. Although DCF methods cannot be directly compared with real options theory, we use a direct comparison in order to highlight the constraints and the limitations of these methods since they are still widely used in the investment analysis. Despite the disadvantages of the DCF methods they are still useful in calculating the starting values used in the real options approach. Results clearly demonstrate the contribution of the real options approach as decision making is drastically alters when real options outcome is considered. Moreover results facilitate a better understanding in terms of public policy and agricultural policy dynamics.
\end{abstract}

Key words: Monte Carlo simulation, farm size, policy, net present value, real options

\section{INTRODUCTION}

The number of farms in Greece has drastically dropped over the past two decades, whereas the average farm size has shown an upward trend. The issue of the appropriate farm size and farm structure has been attracted the interest of agricultural policy both in Europe $^{[1]}$ and the $\mathrm{US}^{[2]}$. This particular interest by policy makers is attributed to a large extends to various income supporting schemes in rural and mountainous areas. Concerns over expected changes in the farm structure were expressed and rise by the public advocating several policies targeted to small farms.

From a methodological point of view, applying traditional DCF methods in farm evaluation is not sufficient enough, as they do not reflect the dynamic and constantly changing business environment. The real options approach in farm evaluation appreciates the value of managerial flexibility and the potential to improve expected returns on the undertaken investment.

In recent years, real options have found ready acceptance in the mining, petroleum, pharmaceutical and life science related industries, where volatility and uncertainty is high and the need for flexibility is at a premium. The real options model has a place in the toolkit of corporate decision-makers because of the high uncertainty and costs of irreversible investments. Executives may informally exercise options whenever they strive for flexible, extensive, and scalable investment. The challenge is now, how to go about institutionalizing the process of recognizing, evaluating, and exercising the options embedded in future investment projects, especially in a market that is turbulent and uncertain, but holds great promises for both short and long terms results.

Empirical studies show that one of the most important drivers of farm growth or decline is financial efficiency ${ }^{[3]}$. The drop in total farm numbers is accelerated by increasing and high input prices and slowed down by increasing and high output prices. However, in general strong commodity markets are not able to stop the decline in the number of small farms. Less favorable economic conditions have a particularly strong negative effect on the number of small farms. Unfortunately most studies neglect the debt structure of farms in their analysis. From the scale economies argument mentioned before one would expect small farms to be less profitable than larger farms and/or having a higher average production cost than larger farms. Often this relationship is confirmed in reality, in particular when land and labour are highly priced, and also in situations of imperfect credit markets. There seems to be an optimal farm size: increasing the farm scale beyond this optimum does not generate scale economies $^{[4]}$. In some cases opposite evidence was found (eg. crop and milk yields that are higher for small

Corresponding Author: $\quad$ Anastasios Ch. Michailidis, Department of Agricultural Products Marketing and Quality Control, Technological Education Institution of Western Macedonia, Terma Kontopoulou st., 53100, Florina, Greece, Tel. 0030-23850-54654 
farms than for large farms). In addition to these economic variables also farmers' attitude and family characteristics are found to influence farm strategy, farm size and legal farm type choice ${ }^{[5]}$.

The main aim of this article is to estimate the optimal size of a typical Greek farm by employing elements of the real options methodology. Monte Carlo simulation was used to value the options as it offers the flexibility to directly simulate the uncertainty factors. Several scenarios are used to estimate the optimal farm size employing both DCF methods and real options.

The rest of the paper is organized as follows: In the next section a brief overview of the general real options model structure is given followed by the theoretical model exposure and the derived results. Finally, the paper ends with the main concluding remarks.

\section{THEORETICAL BACKGROUND}

The selected typical farm, as an investment decision, includes at least three aspects that affect the value of waiting. First, involves some sunk costs, i.e., expenditures that are largely irreversible. This reflects the fact that if a decision were made to reverse the investment decision, the capital could totally recovered. Second, investment activity is inherently risky, as it requires the commitment of resources today for a particular purpose based on expectations of future outcomes for many variables that in general will not in fact be completely materialized. Third, there is typically discretion in the timing of investment, as capital allocation involves not only a decision on the amount but also on when to invest. Waiting to commit resources may be the preferred option because more information will become available that bears on the profitability of the investment.

When all three features are present, the DCF criterion for investment, which is that one should invest at the time when the present value of expected cash flows of a unit of capital equals or exceeds the purchase price and installation cost of the capital, needs to be modified $^{[6]}$. The reason is that when a decision maker sets one's heart on an irreversible investment outlay, he gives up the option of waiting for new information that affects the profitability of the investment. This lost option value is an opportunity cost that needs to be incorporated with the other costs of investment. Consequently, it is appropriate to actually undertake a project only when its present discounted value exceeds the purchase and installation costs by an amount equal to the value of keeping the option open and not committing the expenditures.

But, what is a real option? It is the right - but not the obligation - to acquire the gross present value of expected cash flows by making an irreversible investment on or before the date the opportunity ceases to be available. Although this sounds to be similar to
Net Present Value (NPV), real options only have value when investment involves an irreversible cost in an uncertain environment and the beneficial asymmetry between the right and the obligation to invest under these conditions is what generates the option's value.

The NPV criterion is used extensively in evaluating investment opportunities and is based on DCF methodology ${ }^{[7],[8],[9]}$. The typical cost-benefit model in investment analysis can be represented as a choice between production "with" or "without" a specific investment. The choice between adopting a new farm enlargement project or not can be based on comparison of the incremental investment costs of the new project $I$ and the present value of its incremental net revenue flow, $V$ under certainty:

$$
V=\int_{0}^{\infty} e^{-p t} E\left[\left(P_{t} Q_{w, t}-C_{w, t}\right)-\left(P_{t} Q_{o, t}-C_{o, t}\right)\right] d t
$$

where, $p$ is the real discount rate; $t$ is the time period; $E$ is the expectations operator; $P$ is the output price; $Q$ is the output quantity; $C$ is the variable costs of production; and subscripts $w$ and $o$ indicate production "with" and "without" the investment respectively. The acceptance rule adopts projects where incremental net revenues are greater or equal to incremental investment costs $(V \geq I)$.

Recent developments in investment analysis point out that NPV formulas have shown to be limited when the conditions of irreversibility and uncertainty are present. More specifically, the NPV rule assumes a fixed scenario in which an investor starts and completes a project and garners a cash flow during some expected lifetime without permitting the investor to react in an uncertain and irreversible environment. Contingent claims analysis offers a range of possibilities to examine: investing today, or waiting and perhaps investing later or when the conditions are more favourable ${ }^{[10]}$. It allows uncertainty to influence the adoption decision directly and incorporates an extra value into the cost-benefit structure. Therefore, the simple NPV rule requires modification. The present value of the expected stream of cash from a project not only must be positive but also must exceed the cost of the project by an amount at least equal to the value of keeping alive the investment option ${ }^{[10]}$. Taking option values into account, one would invest in a project only if $V_{t}$ meets or exceeds $I$ plus the value of the option to invest in the future, $F(V)$. Under certainty, the value of the option to invest in the future is equal to zero, so the decision would not be reversed if it is profitable. Under uncertainty, the value of the option to invest in the future can be raised so the optimal time to invest would change.

Dixit and Pindyck $^{[11]}$ suggest an optimal investment trigger using contingent claims analysis that offers a richer framework to evaluate such projects ${ }^{[11]}$. Capital investments or irreversible investment 
opportunities are like financial call options. Therefore, a company with an investment opportunity has the option to spend money now or in the future (the exercise price) in return for an asset of some value (the project). The value of the opportunity to invest is described by the two equations, the value of waiting $\left(B R^{\beta}\right)$ and the value of investing $(R / \rho-K)^{[12]}$.

$$
V(R)= \begin{cases}B R^{\beta} & \text { if } \quad \mathrm{R} \leq \mathrm{H} \\ R / \rho-K & \text { if } \quad \mathrm{R} \geq \mathrm{H}\end{cases}
$$

where, $R$ are the expected uncertain returns from the investment; $B$ is a parameter equal to $(H-\rho K) / H^{\beta[13]} ; K$ is the sunk cost of initiating the investment project; $\rho$ is the opportunity cost of capital or risk-adjusted discount rate.

As discussed in Dixit ${ }^{[12]}$ investments with uncertainty and irreversibility have to be evaluated using a modified rate $\rho$ ' which include the effects of uncertainty and irreversibility. This modified minimum rate of return $\left(\rho^{\prime}\right)$ is used for the determination of the best investment behavior. The relationship between discount rate of return $(\rho)$ and modified rate of return $(\rho ')$ can be understood by examining equation 3 , which describes how optimal rate of return changes as the multiplier $\beta / \beta-1$ increases the value of discount rate $(\rho)$.

$$
\rho^{\prime}=\frac{\beta}{\beta-1} \rho
$$

Pindyck $^{[13]}$ shows that $F(V)$ satisfies the following differential equation:

$$
\frac{1}{2} \delta^{2} V^{2} F^{\prime \prime}(V)+(r-\ddot{a}) V F^{\prime}(V)+r F=0
$$

where, subscripts denote partial derivatives, $r$ denotes the risk-free interest rate, and $\delta$ denotes the opportunity cost of delaying the actual investment. Together with the boundary conditions that, $F(0)=0, \quad F\left(V^{*}\right)=V^{*}-I$ (value-matching condition), and $\mathrm{F}^{\prime}\left(\mathrm{V}^{*}\right)=1$ (smoothpasting condition), equation 4 possesses a unique solution:

$$
\begin{aligned}
& \mathrm{F}(\mathrm{V})=\mathrm{AV}^{\mathrm{a}_{1}} \\
& \mathrm{~V}^{*}=\frac{\hat{\mathrm{a}}_{1}}{\mathrm{a}_{1}-1} \mathrm{E}^{\prime}
\end{aligned}
$$

where,

$$
\hat{\mathrm{a}}_{1}=\frac{1}{2}-(\mathrm{r}-\ddot{\mathrm{a}}) / \hat{o}^{2}+\sqrt{\left[(\mathrm{r}-\ddot{\mathrm{a}}) / \hat{o}^{2}-\frac{1}{2}\right]^{2}+\frac{2 \mathrm{r}}{\hat{o}^{2}}}
$$

Both $\mathrm{F}(\mathrm{V})$ and $\mathrm{V}^{*}$ increase, if $\sigma$ increases. In other words, uncertainty increases the value of an investment opportunities, but decreases the amount of actual investing, since the threshold value, $\mathrm{V}^{*}$, rises.

The optimal timing of an investment, as a tangency between the value of investing $\left(i_{1} i_{2}\right)$ and the value of waiting $\left(w_{1} w_{2}\right)$ to invest, is described in Dixit $^{[12]}$. The optimal investment trigger is at $H$, where the expected returns from initiating the investment are sufficiently high to make it optimal to proceed. To derive the optimal investment rule using dynamic programming, the value-matching condition and the smooth-pasting condition are satisfied simultaneously ${ }^{[12]}$ and the two equations are tangential (figure 1). The value-matching condition indicates that the marginal value of waiting is equal to the marginal value of investing. The solution of the smooth-pasting condition requires a unique point where both the boundary conditions are satisfied. In that point the investment must be implemented and decisions makers must stop keep the option of investing on hold.

$$
H=\frac{\beta}{\beta-1} \rho \mathrm{K}
$$

where, $\rho K$ is the Marshallian trigger and

$$
\beta=1 / 2\left[1+\sqrt{1+\frac{8 \rho}{\sigma^{2}}}\right]>1
$$

The value of $\beta$ is a function of two known or estimate parameters $\left(\rho\right.$ and $\left.\sigma^{2}\right)$. As uncertainty about returns from investing increases, $\beta$ gets smaller and the deference between the Marshallian trigger $(M)$ and the optimal trigger increases. Raising the discount rate increases $\beta$ and reduces the difference between the Marshallian trigger $(M)$ and the optimal investment trigger $(H)$.

A Monte Carlo simulation model is used to estimate the variance on the value of investing in new farm size enlargement project. The value of the opportunity to invest $(\mathrm{V})$ follows a process of geometric Brownian motion (GBM), given by equation $10^{[14],[15],[16]}$.

$$
\frac{d V}{V}=\mu d t+\sigma d z
$$

where, $\mu$ is the constant drift rate, $\sigma$ is the constant variance rate and $d z$ is the increment of Wiener process, $z(t)$. The relationship between $d z$ and $d t$ is given by $d z=e_{t} \sqrt{d t}$ where $e_{t}$ has zero mean and unit standard deviation $\left(e_{t}\right.$ is $N(0,1)$ and $E\left(e_{t} e_{s}\right)=0$, for $\left.t \neq s\right)$. Therefore, changes in $V$ over time are a function of a known proportion growth rate parameter $\mu$, and $\sigma$, which is governed by the increment of Weiner process, $d z$ [10]. It is modeled as the discounted as the discounted sum of random draws from the distribution 
of expected returns from investing $(R)$, annualized and projected into perpetuity. More specific, the opportunity to invest for time $t\left(V_{t}\right)$ is given by equation 11 while for a period hence is $\left(V_{t+1}\right)$ is given by equation $12^{[10],[17]}$

$$
V_{t}=\frac{\left[\frac{\rho}{1-\left(\frac{1}{(1+\rho)^{n-t}}\right)} P V_{t}\right]}{\rho}
$$

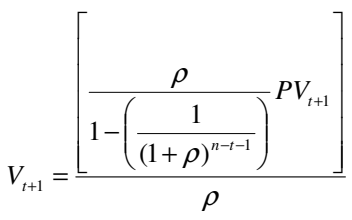

where, $P V_{t}=\sum_{i=0}^{n} \frac{R_{t+i}}{(1+\rho)^{i}}$ and $P V_{t+1}=\sum_{i=1}^{n+1} \frac{R_{t+i}}{(1+\rho)^{i-1}}$ with $R$ the expected return from investing, $\rho$ a discount rate, and $t$ the investment time period.

The trend $(\mu)$ of the geometric Brownian motion process is estimated by

$$
\mu_{V} \approx \frac{1}{N} \sum_{j=1}^{N}\left[\Delta \ln V_{j}\right]
$$

where, $E\left[\Delta \ln V_{j}\right] \Rightarrow 0$ and the variance of the opportunity value to invest is estimated by

$$
\sigma_{V} \approx \frac{1}{N} \sum_{j=1}^{N}\left[\Delta \ln V_{j}-\mu_{V}\right]^{2}
$$

where, $E\left[\left(\ln V_{j}-\mu_{V}\right)^{2}\right] \succ 0$

To calculate the statistics $\mu_{v}$ and $\sigma_{v}$ from simulation data, the mean of $N$ simulated $\log$ differences investing in $t$ and $t+1$ is calculated. The difference between natural logarithms of $V_{t}$ and $V_{t+1}$ gives a discrete estimate of the change in the value of investment opportunity occurring over an increment of a geometric Brownian motion process. An estimate of this discrete difference is simulated over 25,000 iterations. The evaluation of variance of the opportunity to invest is used to estimate the optimum investment trigger under uncertainty and irreversibility.

\section{RESULTS AND DISCUSSION}

The selected farm is located in Velvedo, a town of 4,000 residents in western Macedonia, Greece. The main agricultural products of Velvedo are peaches, apples, plums and vines. A typical farm in Velvedo can be described as an irrigated land of 2.85 hectares. The $76 \%$ of the total cultivable area is used for peach production, the $21 \%$ is used for apple production and the rest $4 \%$ is used for the tillage of other products. In the analysis below the typical farm of Velvedo is handled as an investment opportunity and the farm size as the main independent variable ceteris paribus.

The magnitude of the production cost plays an important role in the farmer's decision, as it constitutes a significant part of the total cost and affects the farms overall economic profitability. Thus, in this work, the farm profitability is assessed by applying DCF methods and a real options approach.

The DCF approach was applied using primary data from a survey and secondary data from the statistical service of the Greek Ministry of Agriculture. The primary data have been gathered through surveys to estimate the investment values (costs and benefits). Both NPV and Internal Rate of Return (IRR) have been applied for a period of one production season (2003) using a discount rate of $6.50 \%{ }^{[18]}$.

The NPV and the IRR measures (including the value of self-employed family work) have been calculated to $€ 12,213.11$ and $7.41 \%$ respectively, suggesting that this particular farm is economically feasible. Several scenarios of larger farm sizes (3.0, 3.5 and 4.0 hectares) and sensitivity analysis (after $\pm 20 \%$ fluctuation of each factor ceteris paribus) demonstrate that larger NPV's and IRR's can be obtain indicating that the farm enlargement is always an acceptable investment.

Afterwards, the real option approach has been applied utilizing the same criteria as above and using as farm size the middle scenario of 3.5 hectares. Monte Carlo simulation is used to designate the mean and the variance of net annual returns of the farm. Net annual returns of the selected farm were determined by 25,000 Monte Carlo iterations through @RISK software ${ }^{[19]}$. The two most important uncertainty sources, of the farm efficiency, are the production level (production source) and the products prices (economic source).

The production level has been modeled as a normal distribution through @BEST FIT software ${ }^{[20]}$. The expected mean production (yield) is calculated using a data set from year 1999 to 2004. Suggestively reported that the expected mean yield for peaches are 25 tones per hectare (standard deviation equal to 7.1) and for apples are 3 tones per hectare (standard deviation equal to 1.2). The selling product price, of the single unit (kilogram), has been modeled as triangular distribution through @BEST FIT software ${ }^{[20]}$. The most likely prices, administered by the central agricultural co-operation, for peaches and apples are $€ 0.21$ and $€ 0.23$ per kg respectively, with expected price ranging from $€ 0.19$ to $€ 0.25$ per $\mathrm{kg}$. In economic terms, the meaning of the prices above is that in scarcity years the selling price of a $\mathrm{kg}$ may be higher than in plethora years. Simulated net annual returns $[E(R)]$ from 
investing in the specific farm have an expected mean equal to $€ 15,750.86$ with a standard deviation of $€ 4,123.12$.

One hundred iterations (simulations) were used to derive the parameters $\mu_{v}$ and $\sigma_{v}$ on the value of the opportunity to invest in the Velvedo's typical farm. The average production cost for the year 2005 is estimated to $€ 12,763.12$. The annuity has been computed assuming a sort-run loan of one years' duration and $6.5 \%$ rate of interest. The Marshallian trigger $(M)$ of the initial cost is equal to $€ 7,413.95$ (Table 1). The net annual returns $(\beta / \beta-1)$ of the investment have to be 1.4832 times greater for the corresponding Marshallian trigger, which means that the net annual returns have to be larger than $€ 10,996.37$ (Figure 1).

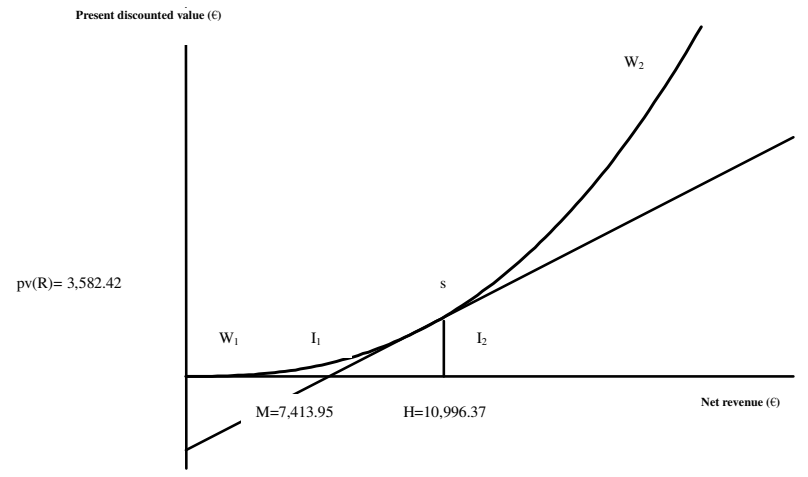

Fig.1: Optimal investment policy

Thus, while investing in the Velvedo's typical farm proved economically feasible according to NPV criterion, it is not economically feasible according to a methodology incorporating real options approach. The simulated annual returns $[E(R)]$ have to be larger than $€ 10,996.37$ according to the optimal investment trigger $(H)$; otherwise they are equal to $€ 1,317.26$. The real options procedure revealed that $[H>E(R)]$, the enlargement project must be postponed and decision makers must keep the option of investing on hold. Thus, adopting a real options approach alters the results and enriches the assessment analysis.

Table 1: Parameters for value of investment opportunity and value of waiting

\begin{tabular}{cc}
\hline Parameters & Values \\
\hline $\boldsymbol{\sigma} \mathbf{2}$ & 0.0201 \\
$\boldsymbol{\beta}$ & 3,0695 \\
$\boldsymbol{\beta} / \boldsymbol{\beta}-\boldsymbol{1}$ & 1.4832 \\
$\boldsymbol{B}$ & $2.1993 \mathrm{E}-15$ \\
$\boldsymbol{\rho}$ & $6.50 \%$ \\
$\boldsymbol{\rho}$ & $8,13 \%$ \\
$\boldsymbol{M}$ & $7,413.95$ \\
$\boldsymbol{H}$ & $10,996.37$ \\
$\boldsymbol{H}-\boldsymbol{M}$ & $3,582.42$ \\
$\boldsymbol{p} \boldsymbol{V}(\boldsymbol{R})$ & $3,582.42$ \\
\hline
\end{tabular}

As one can see in the Table 1 the discount rate of return $(\rho)$ differs from the modified one $\left(\rho^{\prime}\right)$ which includes uncertainty and irreversibility. The modified minimum rate of return ( $\left.\rho^{\prime}\right)$ estimated at $8.13 \%$ has to be used hereafter for the optimal investment decision, instead of the traditional discount rate of return $(\rho)$.

The value of waiting can be illustrating using a diagram (Figure 1) described by Dixit ${ }^{[12]}$. This involves a single project with irreversible expenditure $(I)$ that yields a stream of net revenue $(R)$ which lasts forever. This revenue stream is uncertain with a given probability distribution and is discounted by a positive interest rate $(r)$. The standard present discount approach implies that one should invest whenever $R / r$ exceeds $I$. This involves the implicit assumption that the choice is between investing now or never. However, the additional possibility of waiting can be better than the possibility of not investing at all or implementing the investment immediately.

The optimal waiting time and therefore the optimal trigger point, is determined where the marginal value of waiting is equal to the marginal value of investing. The former is equal to the slope of the value of investing schedule shown as $W_{1} W_{2}$ in Figure 1, where net revenue $(R)$ is on the horizontal axis and the present discounted value of the entire investment project $(R / r-I)$ is on the vertical axis. When the current value of $R$ is very low, the present discounted value of future receipts is also very low, and the $W_{1} W_{2}$ schedules goes to zero from above as $R$ goes to zero. Increasing current values of $R$ raises the present discounted value of the project, resulting in the convex curve $W_{1} W_{2}$. The marginal value of investing is equal to $l / r$ and is equal to the slope of the $I_{1} I_{2}$ schedule, which shows the value of net revenue $(R / r-I)$ as a function of $R$. The optimal value for the net revenue is given by the trigger point which is where the two schedules are tangent to each other at point $I_{2}$. This is known as the smooth pasting condition which equates the marginal value of waiting with the marginal value of investing ${ }^{[12]}$.

Table 2 presents the sensitivity analysis of the variance of net annual returns of the investment. It is obvious that the modified rate of return $\left(\rho^{\prime}\right)$ changes proportionately with the variance changes $(\sigma)$, indicating positive influence. In particular the modified rate of return $(8.13 \%)$ increases $(9.36 \%)$, with standard deviation equal to 0.4 as the variance increases from 0.142 to 0.200 . As well as perceived corresponding increase of the optimal investment trigger $(H)$ from $€ 10,996.37$ to $€ 12,169.18$. Finally, the annual value of net revenue $[p V(H)]$ increases as the uncertainty increases $(\sigma)$.

Table 2: Sensitivity analysis of the variance of net annual returns of the investment ${ }^{*}$

\begin{tabular}{ccccc}
\hline $\boldsymbol{\sigma}$ & $\mathbf{0 . 1 4 2}$ & $\mathbf{0 . 1 0 0}$ & $\mathbf{0 . 1 5 0}$ & $\mathbf{0 . 2 0 0}$ \\
$\boldsymbol{\sigma}^{2}$ & 0.0201 & 0.0100 & 0.0225 & 0.4000 \\
$\boldsymbol{\rho}^{\prime}$ & $8.13 \%$ & $7.07 \%$ & $8.31 \%$ & $9.36 \%$ \\
$\boldsymbol{H}$ & $10,996.37$ & $9,331.14$ & $11,018.48$ & $11,573.98$ \\
$\boldsymbol{p} \boldsymbol{V}(\boldsymbol{H})$ & $3,582.42$ & $1,917.19$ & $3,604.53$ & $4,160.03$ \\
\hline " the following parameters stand constant: $M=7,413.95$ and $\rho=6,5 \%$.
\end{tabular}


Consequently, the question to come is that the value of waiting increases as the uncertainty increases which means that the enlargement of the typical farm must be postponed and the decision makers must keep the option of investing on hold until obtain better information and know how.

The second parameter which influences the optimal investment decision is the discount rate of return. The sensitivity analysis indicates that the value of waiting increases as the discount rate decreases. In particular the value of waiting $[\rho V(H)]$ and the Marshallian point increase as the discount rate of return decreases from $6.5 \%$ to $5.0 \%$. As well as the modified optimal investment policy influenced from the changes of the discount rate of return. Table 3 appears that the annual value of investment increases with a bigger rate than the disease of the discount rate of return which means that it is better to delay the enlargement project of the typical farm in Velvedo.

Table 3: Sensitivity analysis of the discount rate of return $^{* *}$

\begin{tabular}{cccc}
\hline $\boldsymbol{\rho}$ & $\mathbf{6 . 5 0 \%}$ & $\mathbf{5 . 0 0 \%}$ & $\mathbf{8 . 0 0 \%}$ \\
$\boldsymbol{\rho}^{\prime}$ & $8.13 \%$ & $7.15 \%$ & $9.14 \%$ \\
$\boldsymbol{M}$ & $7,413.95$ & $8,936.14$ & $13,048.56$ \\
$\boldsymbol{H}$ & $10,996.37$ & $5,802.16$ & $9,314.92$ \\
$\boldsymbol{\rho} \boldsymbol{V}(\boldsymbol{H})$ & $3,582.42$ & $3,133.98$ & $3,733.64$ \\
\hline${ }^{* * *}$ the following parameter stand constant $\sigma^{2}=0.0201$ &
\end{tabular}

\section{CONCLUSIONS}

With continuing trends in increasing farm size and declining number of farms, the size of operation impact on risk may have significant policy implications. This paper offers an example of a contractual agreement within a farm enlargement project that can be assessed using the real options technique. In addition, an attempt has been made to employ both the NPV criterion and the real options approach to a selected farm and finally to compare results. Monte Carlo simulation was used to value the options as it offers the flexibility to directly simulate the underlying uncertainty factors and to capture a great deal of the complexity in the contractual terms.

This paper used a two step methodology to examine the efficiency of a typical farm in Velvedo, Greece. In the first step, NPV and IRR measures were calculated using a DCF approach. In the second step, real options were used to explore the profitability of the farm size enlargement project. Results indicate that, according to the NPV criterion, the implementation of the Velvedo's farm enlargement is economically feasible. However, assuming the presence of uncertainty, application of a real options approach demonstrates that the NPV may lead stakeholders to faulty decisions, as the investment plan is rejected. The results indicate that the options have a significant value and highlight the fact that ignoring options value process can lead to a significant error. This obviously indicates the importance of combining the NPV criterion in investments with the real options approach.

The first result in the present case is that the value of waiting increases as uncertainty increases, which means that the implementation of the farm enlargement project must be postponed and decision makers must keep the option of investing on hold until they obtain better information and know how. The second result, a negative relationship between the value of waiting and the discount rate, is reminiscent of the influence of the discount rate of return on the optimal investment decision. Actually, the value of waiting and the Marshallian point increase as the discount rate of return decreases. The modified optimal investment policy is also influenced from changes the discount rate of return. In particular, the annual value of investment increases at a greater rate than the decrease in the discount rate of return which means that it is better to delay the implementation of the farm enlargement project.

\section{REFERENCES}

1. Keane, M. and D. Lucey, 1997. The CAP and the Farmer in: C. Ritson and D.R. Harvey eds. The Common Agricultural Policy (2nd edition) Wallingford: CAB International.

2. Summer, D. A., 1985. Farm Programs and Structural Issues. In: B. Gardner, (ed.), U.S. Agricultural Policy: The 1985 Farm Legislation. AEI Symposia series, No. 85c, Washington DC.

3. Schunk, D., 2001. Farm size and farm number development in Illinois: lessons from a dynamic simulations analysis. AEC, FSDSFarming21, September 14, 2001.

4. Carthagne, A, H. Guyomard and F. Levert, 2005. Estimating long run cost functions for French, Italian and German dairy sectors. Paper presented at Braunschweig EDIM seminar.

5. Jongeneel, R. and L. H. G. Slangen, 2005. Explaining the changing institutional organisation of Dutch farms: the role of farmer's attitude, advisory network and structural factors. Paper presented at the EAAE Seminar on Legal Farm Structure Change, Wye, April 2005.

6. Foltz, J., 2003. Entry, exit, and farm size: assessing an experiment in dairy price policy. American Journal of Agricultural Economics, 86: 3-14.

7. Gittinger, J. P., 1986. Economic analysis of agricultural projects, International bank for reconstruction and development, The John Hopkins University Press, Baltimore.

8. Brealey, A. R. and S. C. Myers, 1991. Principles of Corporate Finance (4th ed), McGraw-Hill, Inc. 
9. Luehrman, T. A., 1998. Investment opportunities as real options: getting started on the numbers. Harvard Business Review, July-August: 51-67.

10. Dixit, A. and R. S. Pindyck, 1994. Investment under uncertainty, Princeton University Press, Princeton, NJ.

11. Dixit, A. and R. S. Pindyck, 1995. The options approach to capital investment. Harvard Business Review, May-June: 105-115.

12. Dixit, A., 1992. Investment and hysteresis. Journal of Economic Perspectives, 6(1): 107-132.

13. Pindyck, R. S., 1991. Irreversibility, uncertainty and investment. Journal of Economic Literature, 29: 1110-1148.

14. Black, F. and M. Scholes, 1973. The pricing of options and corporate liabilities. Journal of Political Economy, 3: 637-654.

15. Louberge, H., S. Villeneuve, and M. Chesney, 2002. Long-term risk management of nuclear waste: a real options approach. Journal of Economic Dynamics and Control, 27(1): 157-180.
16. Kassarr, I. and P. Lasserre, 2004. Species preservation and biodiversity value: a real options approach. Journal of Environmental Economics and Management, 48(2): 857-879.

17. Purvis, A., W. G. Boggess, C. B. Moss, and J. Holt, 1995. Technology Adoption Decisions Under Irreveribility and Uncertainty: An Ex Ante Approach. American Journal of Agricultural Economics, August: 541-551.

18. Michailidis, A., 2004. Socioeconomic Evaluation of Large Infrastructure Projects Under Uncertainty: the case of Petrenia Irrigation Dam. Unpublished Ph.D. thesis, Aristotle University of Thessaloniki, Thessaloniki.

19. Palisade Corporation, 2000. @RISK Risk Analysis and Simulation Add-In for Microsoft Excel: A Software Package. Version 4, Newfield, NY.

20. Palisade Corporation, 1996. @BEST FIT Add-In for Microsoft Excel: A Software Package. Version 2, Newfield, NY. 